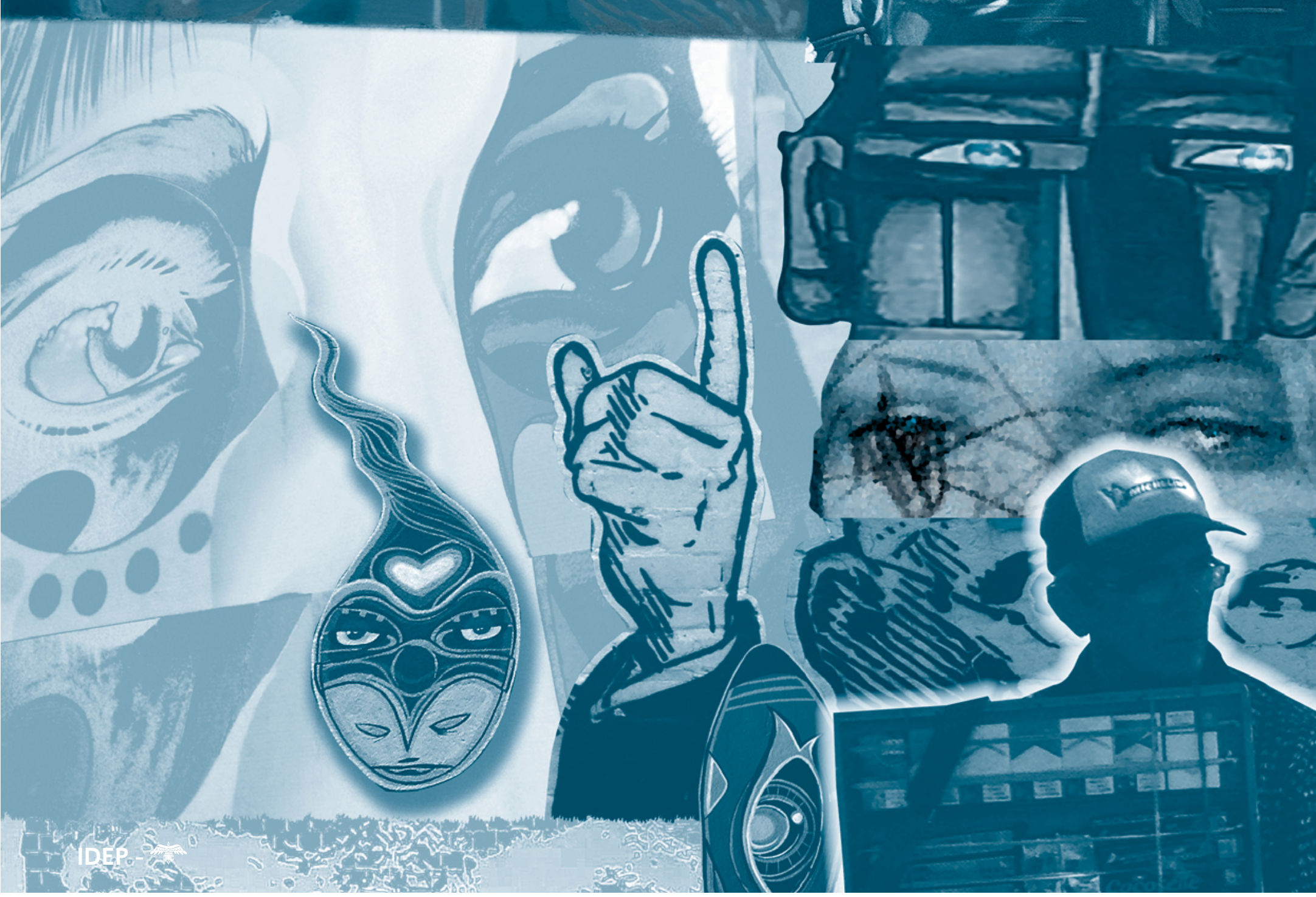

\title{
Resistir en la profesión: una mirada de la formación y la experiencia de maestras recién egresadas
}

Resist in the profession: a look at the training and experience of newly graduated teachers Resistir na profissão: um olhar sobre a formação e a experiência de professores recém-formados

Laura Jessenia Ramírez Gómez Diana Carolina Espitia Artunduaga 
Laura Jessenia Ramírez Gómez ${ }^{1}$ Diana Carolina Espitia Artunduaga²
Licenciada en Psicología y Pedagogía, Universidad Pedagógica Nacional; correo electrónico: lau0101ram@gmail.com

2. Licenciada en Educación Infantil, Universidad Pedagógica Nacional; correo electrónico: despitia1406@gmail.com.

\section{DOI: https://doi.org/10.36737/01230425.v2.n37.2019.2157}

Fecha de recepción: 28 de enero de 2019 / Fecha de aprobación: 30 de agosto de 2019

\section{Resumen}

El presente artículo tiene como propósito ofrecer un panorama de las experiencias laborales desde el testimonio de dos maestras recién egresadas de la Universidad Pedagógica Nacional, cuyas reflexiones se suman a la discusión de todo lo que implica iniciarse en un contexto laboral colombiano, en la ciudad de Bogotá, donde se hace evidente la distancia entre las expectativas de los programas formadores de maestros y maestras y la realidad que día a día se vive en el ejercicio; concluyendo con una reflexión que invita a cuestionarse y seguir insistiendo para reivindicar la profesión.

\section{Palabras clave:}

Formacióndocente, experiencias, contextolaboral colombiano, educación, profesionalización.

\section{Abstract}

This article has the purpose to show an overview of work experiences from the testimony of two teachers newly graduated from Pedagogical Nacional University whose reflections add to the discussion that involves starting out in a Colombian work context in Bogotá, where is evident the distance that creates between the expectations of teachers training programs and the reality that they live daily with the practice. Concluding with a reflection about questioning and follow to insist for reclaiming this profession.

\section{Keywords:}

Training teachers, experiences, Colombian work context, education, professionalization.

\section{Resumo}

O presente artigo tem o propósito de mostrar um panorama das experiências laborais do testemunho de pedagogas recém egresadas na Universidade Pedagógica Nacional, cujas reflexões se somam à discussão de tudo o que implica iniciar em um contexto profissional colombiano na cidade de Bogotá, onde se faz evidente a distância que se cria entre as expectativas dos programas formadores de professores e a realidade que dia a dia se vive no exercício, concluindo com uma reflexão que convida a questionar-se e seguir insistindo para reinventar esta profissão.

\section{Palavras-chave:}

Formação de professores, experiências, contexto profissional colombiano, educação, profissionalização. 


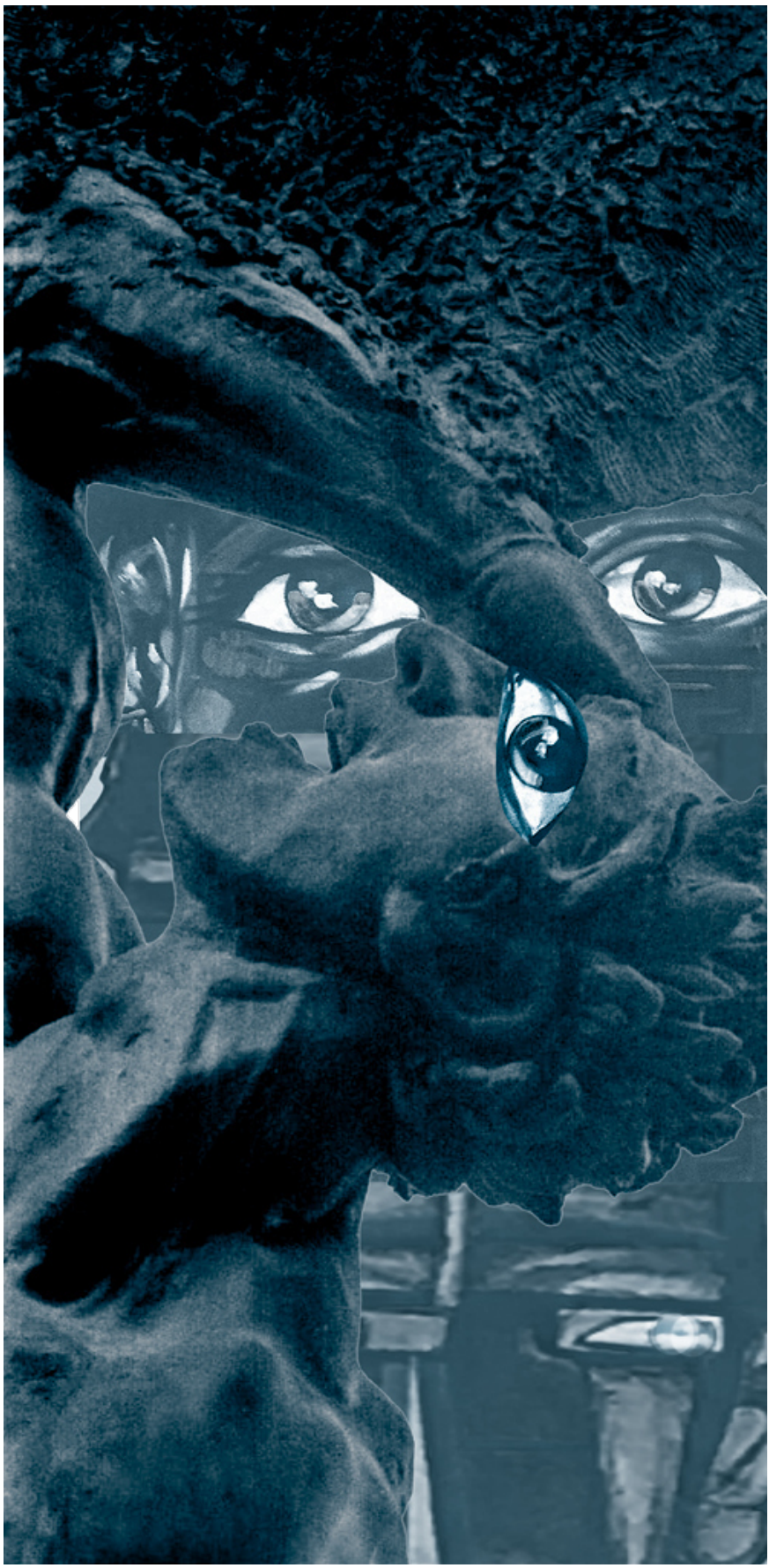

\section{Introducción}

Ser maestros y maestras hoy en Colombia implica, no solo pensar en el ejercicio al interior del campo educativo ${ }^{1}$, sino emprender todo un camino reflexivo desde el momento en que se decide arrancar por un sendero que, siendo desconocido, parece lleno de rosas, para luego, al profundizar, reconocer sus espinas. Atendiendo ese camino es posible vislumbrar lo que significa ser maestros y el interés por descubrir, así como dignificar esta profesión escogida como proyecto de vida.

La historia del maestro está marcada por hechos que han delimitado su ejercicio y que aún le implican, pues, aunque las condiciones han cambiado, todavía se presentan dificultades en el quehacer profesional. Así, retomando a Martínez, Noguera y Castro (1999), se encuentra que, en principio, el maestro emerge como forma de control y vigilancia sobre los problemas sociales, para luego dedicarse a los rudimentos profesionales mediante cartillas y manuales, adquiriendo de algún modo las novedades pedagógicas que llegaban al país; a ello se suma una lucha constante por el pago salarial y el deseo de mostrarse como ser idóneo para ejercer el noble oficio, hechos que le vincularon además a confesar su interés por la educación, llegando incluso a diseñar cartillas para cuando las condiciones económicas eran precarias.

Tales eventos no distan de lo que hoy se ve en cuanto a requerimientos para ser maestro; al respecto, el Decreto 1278, define: "Los servidores docentes y directivos mantienen niveles de idoneidad, calidad y eficiencia que justifican la permanencia en el cargo" (MEN, 2002). Es claro que las exigencias han cambiado, pero permanecen aún las reglas en cuanto al ser y el deber ser; no es que no sea importante, es fundamental que un profesional se especialice en su cargo, pero con la variedad del mundo laboral dichos requisitos se han desplazado y el orden de los mismos

1 Entendemos campo educativo como ese espacio metafórico compuesto por relaciones de poder y discursivas que pueden dominar, producir y reproducir de algún modo un aspecto de la cultura, al respecto señala Díaz, citando a Cox que: "Un campo es el resultado de las relaciones de fuerza y de lucha entre agentes $\mathrm{y} / \mathrm{o}$ instituciones que tienden a conservar o a transformar formas específicas en lo económico, político y cultural" (1993, p. 12).

RESISTIR EN LA PROFESIÓN: UNA MIRADA DE LA FORMACIÓN Y LA EXPERIENCIA DE MAESTRAS RECIÉN EGRESADAS / 165 LaUra Jessenia Ramírez Gómez y Diana Carolina Espitia ARtunduaga 
parece ejercido por las instituciones donde laboran, encontrando entonces salarios bajos, vigilancia de su labor, subestimación en torno a la experiencia, ofertas que revierten las expectativas del egresado y, finalmente, un contexto laboral que exige la vida y entrega del maestro a cambio de poco reconocimiento.

La pregunta por el "resistir en la profesión" es lo que nos atraviesa hoy como maestras frente a la adversidad detectada, no solo en la historia docente, sino en nuestra vida como egresadas; por ello, este artículo citará testimonios de experiencias laborales que dan cuenta de esas vicisitudes y del impulso que nos lleva a resistir. El texto se plantea así: Primero se verá la formación profesional, la forma en que permite desarrollar aprendizajes y expectativas que empiezan a poner en tensión teoría y práctica; luego se explorará la tensión, dando espacio a la experiencia de las egresadas en los escenarios laborales y considerando los antecedentes de oferta de empleo en Bogotá, contrastándolos con los perfiles profesionales planteados por los programas cursados por las autoras; finalmente, se concluye con una reflexión sobre lo que significa ser maestros hoy y la necesidad de resistir en ese camino metafóricamente espinoso.

\section{De la formación y las prácticas profesionales}

Para iniciar, es importante ahondar en el proceso de formación vivido en las instituciones formadoras de maestros(as), pues ellas brindan las primeras bases para entender el sentido de ser parte de esta profesión; además, allí se adquieren conocimientos y saberes fundamentales que aportan a la labor y permiten una reconfiguración del sujeto en formación, pues implican su esfera personal, académica y social. Es decir que, ingresando a este campo del saber, es probable construir una idea de educación y de maestro, que no es única o estática, sino que más bien está influida por una proliferación de construcciones alrededor del ser y el deber ser.

Tal proliferación es anunciada por Álvarez (2010), quien la propone como campo que facilita comprender cómo el ingreso de estudiantes a la universidad les hace parte de un entramado de constructos y, en consecuencia, del campo, en la medida en que empiezan a participar de las discusiones y luchas para entender, en este caso, la educación, la pedagogía y el ser maestro. Dichos cambios en las nociones sobre la docencia se dan debido a las "posiciones, oposiciones y combinaciones" (Díaz, 1993, p. 15) halladas en los discursos al interior de un espacio formativo como la universidad. Ahora, aunque estas premisas establecen como punto álgido el dominio de los intelectuales (Díaz 1993), no se desplaza el estudiante y/o al maestro profesional, sino que le hacen parte del campo en tanto reproductor, pero que reflexiona los discursos al interior de los distintos escenarios.

La idea de educación y de maestro se re-construye al igual que ocurre con las nociones sobre la enseñanza, el aprendizaje, la pedagogía, los mismos estudiantes y hasta la legislación que nos rige. Hay una trasformación de los sujetos, pero no solo desde la adquisición de saberes, sino desde la labor que empieza a ser reflexionada por quienes se forman como maestros; es decir que se da paso al desarrollo de un pensamiento acerca de lo que hace y puede lograr en la labor. Ese "hacer" y "lograr" no podría más que estar supeditado a los requerimientos y propósitos de los programas de formación en cuanto al perfil de los estudiantes, así como de los egresados. Para ampliar la discusión es necesario entonces remitirse a estos perfiles, al menos en las licenciaturas a las que estamos adscritas. Por ello se presentan a continuación:

Programa: Licenciatura en psicología y pedagogía: Su objeto es la formación de profesionales de la educación que consigan identificar, dinamizar y apoyar el hecho educativo a partir de los procesos de enseñanza, aprendizaje, currículo y gestión y que estén comprometidos con la reflexión, el fortalecimiento y la transformación de los procesos de enseñanza y de aprendizaje en los diversos contextos educativos del país [...] El licenciado en Psicología y Pedagogía puede ejercer su labor profesional en distintos escenarios educativos tanto dentro como fuera del ámbito escolar en entidades oficiales y privadas, su campo de acción se centra en tres líneas de trabajo: investigación, docencia y gestión (UPN, sf.a).

Programa: Licenciatura en Educación infantil: Es un/a profesional que, en razón a su compromiso y posicionamiento crítico frente a la educación y a las realidades de las infancias del país, puede incidir en éstas y sus entornos familiares, escolares y comunitarios, mediante alternativas educativas, pedagógicas, políticas, sociales y culturales. Es un maestro con actitud investigativa que identifica problemas conceptuales y prácticos, referidos a la complejidad y las necesidades formativas de las infancias en sus múltiples contextos, desde discursividades emergentes que reconocen la diferencia, la diversidad, el género, el cuidado y el medio ambiente entre otras. Puede ejercer funciones de docencia, investigación y gestión, en colegaje con otros profesionales desde la intersectorialidad y la interdisciplinariedad (UPN, sf.b).

Como se observa, hay variedad en la propuesta para el hacer de ese maestro, un hacer que no deriva en mero activismo, sino que se proyecta hacia la idea de construir país, de reflexionar sobre su práctica para mejorar y crecer profesionalmente, porque no 
es un secreto que la práctica fue y es el insumo más grande para comprender las distintas realidades que se pueden transformar, así es planteado en uno de estos escenarios, que busca: "Reconocer en las prácticas formativas espacios de reflexión, investigación y producción de conocimiento pedagógico (Martínez, 2015, p. 1), un contexto abierto a la reflexión, dispuesto de experiencias que reconfiguran los modos de pensar la pedagogía, la educación, la escuela y al maestro(a); en tal sentido:

La orientación práctica o reflexión en la acción, surge como una respuesta a la necesidad de profesionalizar al maestro y como propuesta que tiene la intención de superar la relación lineal y mecánica entre una teoría o conocimiento científico y una práctica de aula supeditada a éste [Desde este punto] el proceso reflexivo debe servir para optimizar la respuesta docente ante situaciones reales, teniendo en cuenta que el profesional debe poner sus recursos intelectuales al servicio de la situación, de manera que a través de un proceso - que debe ser semiautomático - de análisis y búsqueda de estrategias o soluciones, se satisfagan las necesidades reales del aula de forma eficaz (Schön, 1987, p. 1).

En ese sentido, la práctica se vuelve inherente al ser maestro, en la medida en que se convierte en escenario real y cotidiano desde el cual es posible actuar, tomar decisiones y generar cambios que incidan en su forma de concebir la educación. No obstante, el perfil del estudiante se tensiona en el momento que ingresa a las prácticas universitarias.

Con el propósito de formar integralmente, los programas académicos ofertan estos espacios en los que el estudiante en formación tiene la posibilidad de poner en juego esos saberes adquiridos, construidos y transformados, lo cual se expresa como: "Diseñar, implementar y evaluar estrategias pedagógicas y didácticas que apoyen la intención formativa de la institución" (Martínez, 2015, p. 1), es decir, las acciones de ese maestro en formación se dirigen al beneficio de la población y de la institución en general. Sin embargo, vale la pena aclarar que estos espacios no siempre están abiertos a propuestas y es allí cuando la idea del hacer intencionado sufre un choque; como ejemplo, vale la pena analizar la siguiente situación:

La pretensión siempre ha sido el abordaje de los grados octavo desde la prevención en el consumo de sustancias; las dinámicas e intencionalidades eran distintas al inicio del proceso, entendiendo que en primera medida lo que se quería potenciar en los estudiantes era el reconocimiento de la relación mente-cuerpo, la adquisición de hábitos y el manejo del tiempo libre desde una propuesta de alguna manera indirecta, es decir que las acciones que se iban a encaminar no apuntaban directamente al consumo, sino a la comprensión de las temáticas anteriormente mencionadas, desde la lectura de mitos griegos y el conocimiento de personajes que manejaran distintos hábitos de estudio, al igual que el manejo del tiempo libre. No obstante, por razones institucionales, que obedecen a los criterios de los orientadores y la misma institución, se corría el riesgo de que la propuesta terminara encaminada hacia el fortalecimiento de la lectura y la escritura, por lo que se decide hacer una variación (Castañeda, Chauta y Ramírez, 2016, p. 6).

Lo anterior no es más que el testimonio de una práctica que debió cambiar totalmente su propuesta en un colegio en Bogotá; no se podía abordar la prevención del consumo desde una invitación escritural y literaria, debía tocar directamente el tema de las sustancias. La cuestión es que pareciera siempre existir el temor de que lo tratado indirectamente implica la no obtención de resultados; sin embargo, más allá de negarse y exigir que los estudiantes expongan alcances, la práctica debería estar abierta a propuestas, porque es posible abordar la prevención, o cualquier otro tema de hoy, desde distintas áreas, siempre y cuando todo tenga un fundamento e intencionalidad.

La idea de estas prácticas no es solo realizar una labor ligada a un proyecto pedagógico, sino reflexionar el propio quehacer para mejorar y entender, así como para proponer un pensamiento en torno a lo que es ser maestro en formación. No obstante, este ejercicio, en nuestro caso, llegó a un punto que pareció "insuficiente", pues se cuenta con poco tiempo para cumplir la labor, en algunas licenciaturas tan solo dos días, tal vez tres y, para el caso de otras, un día a la semana; quizá institucionalmente se pensó que bastaba con dicho tiempo, pero la realidad es que no.

Uno de los grandes choques en la formación para los egresados es la práctica, porque más allá de construir proyectos pedagógicos y de contar con algunos espacios para ejecutarlos con la población abordada, no se tiene espacio como maestro(a), pues la cuestión práctica se convierte en responder a los alcances del proyecto, mientras que el fortalecimiento en la acción viene a darse después, cuando se enfrenta el mundo laboral.

Desde la perspectiva personal, si hubo un error en las prácticas realizadas en la universidad, tal vez fue el de tener infinidad de expectativas, pero ser maestro implica esperar, supone tener idea de lo posible alrededor de las prácticas, que son afectadas por esos encuentros y desencuentros entre lo que se lee en la carrera y la vida real; la disociación es más frecuente que la relación. Sin embargo, hoy, estando del otro lado, buscamos bases, releemos desde ese afán de encontrarnos y recuperar todo eso que pensábamos cuando éramos maestras en formación, porque ser maestros(as) en la labor también implica "pincharse con las espinas". 


\section{De la formación al contexto laboral: ¿Qué nos dice la experiencia?}

Incursionar en el campo laboral colombiano supone un desafío para los maestros y maestras recién egresados, pues no siempre se "está preparado(a)" para todo lo que implica en términos profesionales, personales y de experiencia. Este camino inicia con la búsqueda de espacios que nos acepten a pesar de que, desde su perspectiva, no contamos con la "experiencia" suficiente para abordar un grupo, un proyecto o para hacernos responsables de todas las labores asignadas; más aún si se tiene en cuenta que algunas de esas funciones pueden no tener mucho que ver con nuestra profesión, vista desde los perfiles del egresado señalados anteriormente.

Así, es preciso empezar por definir o delimitar el término "experiencia”, ya que, además del título, es uno de los principales requisitos solicitados en las ofertas laborales. Retomando a Larrosa, podríamos decir que la experiencia es eso "que me pasa”; no lo que pasa, sino "eso que me pasa". Cuando el autor expresa el término "me pasa" hace de la experiencia un asunto personal, subjetivo y hasta intransferible, atraviesa a un sujeto en particular, en consecuencia:

No hay experiencia, por tanto, sin la aparición de un alguien, o de un algo, o de un eso, de un acontecimiento, en definitiva, que es exterior a mí, extranjero a mí, extraño a mí, que está fuera de mí mismo, que no pertenece a mi lugar, que no está en el lugar que yo le doy, que está fuera de lugar (Larrosa, 2011, p. 2).

Decir que la experiencia es subjetiva no significa que su origen sea el sujeto, porque ella es externa a él en tanto deviene del exterior, por ello su prefijo es "ex"-periencia; el sujeto es el lugar por donde pasa y el entorno su origen. La experiencia solo pertenece al sujeto que la vive, lo cual resulta incomprensible para los empleadores y configura una coyuntura en el empleado maestro, pues, si atendemos a Larrosa, la práctica sí sería una experiencia, en tanto viene del exterior y genera un cambio en el sujeto; al respecto el programa de prácticas de la Licenciatura en Educación Infantil de la UPN, establece: "Se espera que el proceso formativo que se consolida en el espacio académico de práctica, posibilite en los docentes en formación una mirada que tensione la cotidianidad escolar a partir de la consolidación de un discurso pedagógico" (Martínez, 2015); pero, esta experiencia no es validada como tal, pues no ha sido obtenida después del grado. Claramente, en Colombia, el título demarca un antes y un después que incide en un contrato laboral; veamos la siguiente oferta:
Estudiante de últimos semestres de pre-escolar, psicopedagogía, áreas afines con la educación, se requiere para auxiliar en institución educativa en el norte de Bogotá, con excelente comprensión de lectura y manejo del inglés. Horario de lunes a viernes de 2:30 a 7:00 pm, contrato a término indefinido inferior a un año. Funciones: calificar material de español e inglés con los solucionarios respectivos y orientar con pistas como le enseñaremos a alumnos (niños, jóvenes y adolescentes). NO ES PREPARANDO NI DICTANDO CLASE. Tipo de puesto: Medio tiempo. Salario: \$420.000 a \$520.000 /mes (Computrabajo, 2019).

Aquí cabe preguntarse: ¿Por qué solicitar estudiantes de últimos semestres?, esto parece ser suficiente para el empleador, en la medida en que los últimos años cursados indican que la persona ha tenido experiencias por su antigüedad en la carrera; pero al no contar con el título profesional su sueldo y condiciones pueden verse afectadas. Si se analiza cada oferta, se termina, dependiendo del cargo, exigiendo lo mismo a un estudiante que a un profesional, porque no hay un criterio exacto que determine algo distinto; por ejemplo, la carga laboral es la misma para licenciadas o estudiantes de Educación Infantil; se vería distinto si el criterio especificara que su cargo será de auxiliar, lo cual demandaría asuntos referidos a "acompañar a la maestra titular en las actividades, salidas y demás situaciones".

La experiencia se convierte entonces en un aspecto que en cierta medida limita el acceso a un puesto de trabajo una vez se obtiene el título. Dos de las bolsas de empleo más grandes a nivel nacional incurren en este requisito de forma precisa y reiterativa, incluso las mismas ofertas se anotan en mayúsculas: "SI NO CUMPLE CON LOS REQUISITOS ABSTÉNGASE DE APLICAR”. Citando el primer anexo, los requisitos también terminan siendo ambiguos, no se sabe con claridad el perfil que requerido:

Niñeras, técnicas profesionales en atención integral a la primera infancia o en preescolar, pedagogas infantiles, licenciadas en educación infantil y personal en áreas afines para desempeñar el cargo de Nanny Educadora de Primera Infancia [Realmente lo que interesa es] Con experiencia mínima de 1 año comprobable con niños de la primera infancia en actividades educativas y de cuidado con niños de (0-5) años (Anexo 1).

Entonces cabe preguntar: ¿Qué tipo de profesionales buscan las escuelas, instituciones o proyectos educativos? Es una cuestión que ha resonado durante la indagación personal por un escenario que acepte nuestro título y nuestra "poca experiencia”, sin caer en esa idea de aceptar el empleo por el temor a no conseguir, lo cual perjudica la forma en que se asume el ser maestro, porque 
al permitir un trabajo bajo esas condiciones (salarios, horarios) se legitima la permanencia y vigencia de esos lugares, es decir, aceptar, solo por no quedar desempleadas, también hace inferior nuestra labor.

Por otra parte, también vale la pena revisar los requisitos asociados con la jornada laboral y el sueldo: "El contrato es por prestación de servicios, se organiza en planes mensuales con un salario de $\$ 1.000 .000$, acorde con una asignación lunes a viernes de 7:00 a.m. a 5:00 p.m. y puede ser ajustado acorde a los planes con distinta demanda". Visto lo anterior, resulta importante ver que, en Colombia:

El contrato por prestación de servicios es de carácter civil y no laboral, por lo tanto, no está sujeto a la legislación de trabajo y no es considerado un contrato con vínculo laboral al no haber relación directa entre empleador y trabajador, por ello, no cuenta con período de prueba y no genera para el contratante la obligación de pagar prestaciones sociales (Elempleo.com, 2010).

Por su parte, el Código Sustantivo del Trabajo (1951) expresa que una persona vinculada bajo la figura de contrato en esta modalidad no tiene la obligación de cumplir horario. Sin embargo, en la oferta se hace énfasis en un contrato por prestación de servicios y un horario que supera el límite legal: "7:00am- 5:00pm"; recordemos que el Artículo 161 establece "La jornada laboral máxima en 8 horas diarias y en 48 horas semanales" (Ministerio del trabajo, 1951); es posible llegar a un acuerdo de jornada inferior, pero nunca superior, a pesar de ello la oferta supone alrededor de 10 horas de trabajo, sin contar desplazamientos, por un sueldo de 1'000.000 de pesos, del cual habría que descontar, además, la seguridad social, pues la persona deberá correr con dichos gastos: Salud, ARL, pensión.

Como es evidente, en las ofertas referenciadas los profesionales se ven expuestos a trabajar en lugares que no están de acuerdo con lo establecido en la ley, ello supone una devaluación de la formación recibida como profesional, porque la falta de claridad en los perfiles solicitados lleva casi a la obligación de trabajar en esas condiciones para ganar "algo de experiencia", pues, además, solo algunos escenarios, y bajo algunas condiciones, tienen en cuenta la experiencia en práctica.

En los dos portales de empleo citados se lleva a cabo un proceso que implica la inscripción de la hoja de vida; los empleadores también deben estar inscritos en el portal y van evaluando, de acuerdo a sus criterios, los diferentes perfiles que han solicitado. No obstante, el llamado a la entrevista es solo una parte del camino, pues cuando los profesionales son citados ocurren algunas variaciones en el contrato y eso genera inseguridad para tomar lo oferta, pues no se cuenta con la precisión necesaria. En tal sentido, cobran valor las estadísticas reveladas por el Empleo.com frente a la oferta y demanda de empleo para el año 2018; en Colombia:

Por nivel educativo, los universitarios son los que más están buscando trabajo (1'183.328 de ellos aplicaron a un trabajo en diciembre). Después se ubicaron los técnicos laborales (301.896), perfiles con preparación media (284.485) y tecnológica (268.961), quienes precisamente suelen ocupar las vacantes para cargos operativos. Para personas que tienen maestrías y doctorados la oferta fue mucho menor y así también el número de aplicaciones (Borda, 2018).

Las personas que han culminado una carrera universitaria salen a enfrentar un país que, en términos de empleabilidad, no está preparado para recibirles, por ello es frecuente ver profesionales desempeñándose en otras áreas u oficios, mientras que la formación técnica o tecnóloga tiene mayor acogida, pues, siguiendo las cifras citadas, aunque son menos quienes aspiran, cuentan con mayores oportunidades: "En el informe el mayor número de ofertas que se están presentando son para perfiles operativos, estos puestos son el motor de las principales industrias” (Borda, 2018).
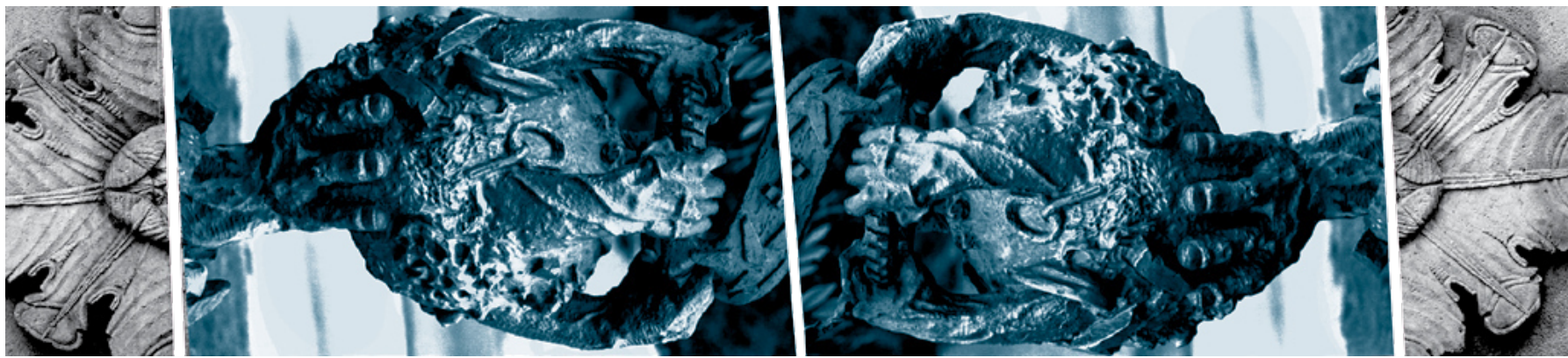

RESISTIR EN LA PROFESIÓN: UNA MIRADA DE LA FORMACIÓN Y LA EXPERIENCIA DE MAESTRAS RECIÉN EGRESADAS / 169 Laura Jessenia Ramírez Gómez y Diana Carolina Espitia Artunduaga 


\section{Conclusiones}

Como se ha visto, grandes dificultades rodean las realidades de los maestros en el país, entre ellas, pareciera que interesa más una "buena palanca" que el mismo título profesional y resulta curioso, además, el escenario que permite a otros profesionales, sin formación docente, la posibilidad de ser contratados para distintos cargos asociados con la profesión; vemos ingenieros, médicos, periodistas, terapeutas, administradores, etc., dando clase en las instituciones, liderando proyectos y planteles educativos.

No se quiere decir que esté mal, al contrario, es necesario involucrar otros profesionales en el campo educativo, el punto de discusión es la seriedad con que se asuma el acto de educar: si se trata de evitar el desempleo por "ganar experiencia" o si en realidad existe un interés por la carrera. En el primer caso se debe tener en cuenta que, para el mes de marzo de 2019 , la cifra nacional de desempleo fue del 10.8\%; lo interesante, o complejo, es que estas cifras aumentaron hasta llegar, aproximadamente, al $12.0 \%$ (DANE, 2019); estadísticas difíciles, en la medida en que una parte de la población se encuentra sin ocupación y sin la posibilidad de devengar un sueldo que brinde mejores condiciones, aún sin discutir los salarios y costos de vida en el país, que se incrementan con mayor rapidez día por día.

Las cifras exponen una realidad que toca a los maestros porque, sin lugar a dudas, muchos se encuentran entre la población desocupada, un desempleo que además se vincula a aspectos como la falta de claridad en cuanto a los requisitos, aspecto revisado anteriormente, y con un escenario que implica a esos profesionales de distintas áreas. En ese sentido, a medida que se ha consolidado la profesión docente se han acogido distintas propuestas de formación como los cursos de pedagogía, que buscan capacitar a profesionales de otras disciplinas para que puedan ser maestros; asunto coyuntural, porque las razones para tomar dichos cursos varían entre un gusto por la enseñanza y "no morir de hambre".

$\mathrm{Al}$ respecto, bien vale la pena recordar lo que señalara Freire para discutir la situación de los maestros en Brasil: "Vine a hacer el curso de magisterio porque no tuve otra posibilidad" (1993, p. 52); un escenario familiar para nuestro país, donde el magisterio se ve como una "salida" económica muy asequible al momento de elegir profesión y buscar un trabajo, esto, a pesar de enfrentar condiciones de empleabilidad poco favorables comparadas con otras profesiones; escenario replicado por Freire cuando recuerda:

Incluso es posible que algunos cursos de capacitación del magisterio sean, irresponsablemente, simples "tragamonedas" [...] pero no significa que la práctica educativa llegue a ser una especie de marquesina bajo la cual la gente espera que pase la lluvia y para pasar una lluvia bajo una marquesina no necesitamos formación (1993, p. 52).

Este panorama es el que permite problematizar la situación aquí, preguntando qué debería ocurrir con todos los maestros que año tras año se gradúan en las universidades: ¿En qué se supone que deberíamos aplicar y ejercer todo lo que nos brinda la formación?; si somos los más idóneos para liderar la educación: ¿Por qué es tan restringido o desvalorizado el acceso a nuestro propio campo laboral? Parece que nos hubieran desterrado, que no confiaran en nuestras capacidades y posibilidades. Nosotros no podemos hacer la labor del médico, del ingeniero, del terapeuta, pero ellos, o cualquiera en realidad ¿pueden ser maestros en Colombia?

Cada pregunta expuesta afecta el ejercicio de ser maestros(as), no en el sentido de juzgar lo que hacemos o lo que no somos capaces de hacer, sino de darnos un lugar, de insistir en este tipo de preguntas, porque solo quienes lo hacemos tenemos claro el significado de trabajar por un sueldo mínimo, hacer voluntariados para conseguir un mejor empleo, trasladarnos de un extremo de la ciudad a otro para dar una clase, enfrentar la tensión de los ambientes laborales, trabajar sintiéndonos observados y criticados por la institución, los padres de familia, la ley y nuestros mismos colegas.

A nivel personal, tuvimos que trabajar como acompañantes terapéuticas "sombra", realizando un proceso de inclusión y adaptación curricular para población con necesidades educativas especiales; también en una línea de atención ${ }^{2}$ para la infancia y la juventud, ocupación más o menos pedagógica, en la medida en que implicó buscar herramientas y modos de vincularse desde el saber para orientar niños y jóvenes del país, así: ¿Cuántas personas piensan cómo enseñar u orientar un niño por teléfono o resuelto dudas juveniles en cuanto al sentido de la vida, las oportunidades o la sexualidad por ese canal? Estas son solo otras prácticas vividas, a pesar de saber que no se daban en un aula, de que no eran los contextos idóneos para educar, que el pago no era el mejor y se pensó que no sería un escenario para llevar a cabo la labor ${ }^{3}$.

Al tiempo, ofrecer nuestros servicios profesionales voluntariamente a cambio de una experiencia de intercambio cultural y suplementos básicos, también se convirtió en otra forma de abrirse camino en

\footnotetext{
Línea 141 del Instituto Colombiano de Bienestar Familiar.

Uno de los objetivos principales era utilizar los protocolos de atención, preguntas filtro y respuestas a las preguntas más frecuentes de acuerdo al tipo de petición realizada.
} 
la profesión. El voluntariado se realizó con la Fundación América Solidaria, cumpliendo algunos requisitos necesarios para el programa: Tener experiencia previa en temáticas de voluntariado y superación de pobreza, contar con un título profesional y la libertad para destinar un año al servicio como voluntario, además de contar con la nacionalidad de algún país americano.

Luego de una búsqueda de empleo infructuosa, una de nosotras se vinculó al programa apenas se graduó, pasando por todo el proceso de selección. No tenía más experiencia que la práctica profesional, un insumo más que suficiente porque allí abordó distintas poblaciones en múltiples contextos. La labor estuvo sujeta a un proyecto social investigativo para dar cuenta de las necesidades de la comunidad, ideando estrategias para superar la pobreza. Sin embargo, aunque el voluntariado se configura como "experiencia", no suele ser atractivo para los empleadores porque la profesión muchas veces se ve solo en términos escolares, desdibujando el hecho de que los maestros(as) pueden ejercer su labor también desde otros lugares en los que su acción les sitúa como agentes de cambio, capaces de investigar, reflexionar y extender su práctica a otras infancias, juventudes, comunidades y poblaciones.

En los dos casos fue necesario planear e improvisar, porque no basta con lo aprendido en la universidad ni con querer hacer bien las cosas, siempre se exige más. No dudamos que esto nos permitió aprender y, en parte, asumir nuestro rol docente, pero, como se ha reiterado durante el texto, son asuntos que no dejan de tocarnos como maestras, profesionales y egresadas.

El papel de las instituciones formadoras es vital, ser maestro se piensa al leer los clásicos de la pedagogía, a los pedagogos críticos e innovadores, a los que promueven una enseñanza sin escuelas, a los mismos compañeros en sus proyectos de grado, sus respuestas nos pensamos viendo a quienes nos formaron deseando ser, o no, como ellos; somos maestros cuando leemos nuestra lucha diaria por un trabajo que dignifique la profesión, cuando indagamos nuestra propia labor que, de uno u otro modo, aporta a la constitución de otros seres y, por qué no, cuando estudiamos a Agustín Joseph de Torres, quien, como nosotras, quiso acabar sus urgencias y tener una mejor calidad de vida. En tal sentido, podríamos decir que las instituciones nos olvidan al no posibilitar espacios que incentiven un vínculo más amplio con el mundo laboral una vez se egresa; también hay un olvido del Estado para con quienes promueven la educación nacional y, si el panorama es tan gris, ¿qué nos hace resistir? Quizá nos mueva la esperanza de pensar que algún día daremos vuelta a estas situaciones, de creer que aún son posibles otras formas de hacer escuela, de educar y de formarnos porque, aunque no sea la profesión mejor pagada, es la que mejor permite estar en contacto con las realidades sociales de niños, niñas, jóvenes y familias. Ser maestro(a) hoy es estar conectados y actualizados con el mundo, entender que los modos de actuar inciden en el otro. El maestro no deja de ser una figura dotada de poder y acción, un retórico por naturaleza, capaz de llegar a cualquier lugar con su discurso.

Tal vez pasen años, no solo para lograr un buen trabajo, sino para un real reconocimiento de la profesión, en términos de que Estado y sociedad entiendan lo importante de formar a esos profesionales para que puedan ejercer $\mathrm{y}$ hacer valer sus derechos como maestros(as). Desde aquí invitamos a quienes se están formando, a los recién egresados y a los profesionales activos a no desfallecer, a insistir, a escribir, a pensar nuestro ejercicio, leer, cuestionar, indagar y experimentar; porque, más allá de la escuela, es en esos escenarios donde también nos construimos y existimos. Insistir permite existir. La voz de nuestros maestros aún está en nosotras, no solo nos formamos como licenciadas, aprendimos a amar esta profesión de altas y bajas, de aciertos y fracasos. A pesar de las espinas, de las falencias en formación, de los obstáculos laborales, la palabra escrita y la voz son nuestro lugar de resistencia, de empoderamiento para evitar el olvido. 


\section{Referencias}

Álvarez, A. (2010). Del campo intelectual de la educación al campo conceptual de la pedagogía: vigencia de un debate. Bogotá. Manuscrito no publicado.

América solidaria. (2019). Voluntariado. Obtenido el 15 de Mayo de 2019 desde http://americasolidaria. org/voluntariado-internacional/

Borda, J. (2018). Empleo: las profesiones más demandadas por las empresas. Portafolio. Obtenido el 15 de Mayo de 2019 desde https://www.portafolio.co/economia/empleo/las-profesiones-masdemandadas-por-las-empresas-513431

Computrabajo. (2019). Ofertas laborales. Obtenido el 13 de Mayo de 2019 desde https://www.computrabajo. com.co/

Castañeda, X., Chauta, D., y Ramírez, L. (2016). Fortalecimiento de competencias intrapersonales. Bogotá. Manuscrito no publicado.

DANE, (2019). Empleo y desempleo. Información agosto de 2019. Obtenido desde https://www.dane.gov.co/ index.php/estadisticas-por-tema/mercado-laboral/empleo-y-desempleo

Díaz, M. (1993). El campo intelectual de la educación en Colombia. Cali: Universidad del valle.

El empleo.com. (2010). Detalles del contrato de prestación de servicios. Obtenido el 14 de Mayo de 2019 desde https://www.elempleo.com/co/noticias/investigacion-laboral/detalles-del-contrato-de-prestacionde-servicios-3802

Freire, P. (1993). Cartas a quién pretende enseñar. México: Siglo XXI.

Larrosa, J. (2011). Experiencia y (alteridad) en educación. Obtenido el 11 de Mayo de 2019 desde http:// www.ceip.edu.uy/documentos/2018/ifs/dapg/materiales/Jorge_Larrosa_Experiencia_y_alteridad. pdf.

Martínez, A. (2015). Programa de prácticas: Práctica proyecto de grado I. Educación infantil. Bogotá: Universidad Pedagógica Nacional.

Martínez, A. (2016). Alberto Martínez Boom. Obtenido el 20 de Enero de 2019 desde http://www. albertomartinezboom.com/

Martínez, A., Noguera, C., y Castro, O. (1999). Maestro, escuela y vida cotidiana en Santafé colonial. Bogotá: Sociedad Colombiana de Pedagogía.

MEN. (2002). Decreto 1278 de 2002. Obtenido el 11 de Mayo de 2019 desde https://www.mineducacion. gov.co/1621/articles-86102_archivo_pdf.pdf

Ministerio del trabajo. (1951). Código sustantivo del trabajo. Obtenido el 13 de Mayo de 2019 desde http:// www.mintrabajo.gov.co/normatividad/leyes-y-decretos-ley/codigo-sustantivo-del-trabajo

Programa de prácticas. (2015). Licenciatura en educación infantil. Bogotá: Universidad Pedagógica Nacional.

Schön, D. (1987). La formación de profesionales reflexivos. Hacia un nuevo diseño de la enseñanza y el aprendizaje de las profesiones. Barcelona: Paidós.

Universidad Pedagógica Nacional (UPN). (sf.a). Licenciatura en Psicología y Pedagogía. Perfil Profesional. Obtenido desde http://educacion.pedagogica.edu.co/vercontenido.php?idp=395\&idh=12096.

Universidad Pedagógica Nacional (UPN). (sf.b). Licenciatura en Educación Infantil. Perfil del aspirante y del egresado. http://educacion.pedagogica.edu.co/vercontenido.php?idp=395\&idh=398\&idn=10352 


\section{Anexo 1}

Nannys, entidad especializada en prestar servicios de cuidado, estimulación y desarrollo integral para la primera infancia requiere: niñeras, técnicas profesionales en atención integral a la primera infancia o en preescolar, pedagogas infantiles, licenciadas en educación infantil y personal en áreas afines para desempeñar el cargo de Nanny Educadora de Primera Infancia, mujeres desde los 25 a 50 años (preferiblemente madres) con experiencia mínima de 1 año comprobable con niños de la primera infancia en actividades educativas y cuidado con niños de (0-5) años, con vocación, excelente actitud, disposición y compromiso, motivadas por el aprendizaje continuo, con habilidades para el manejo de diversos comportamientos propios de los infantes. Con energía para prestar un excelente servicio de cuidado, estimulación y potenciación del desarrollo. El contrato es por prestación de servicios con un salario de \$1.000.000, con una asignación lunes a viernes de 7:00 a.m., a 5:00 p.m. Este puede ser ajustado. Agradecemos aplicar a esta convocatoria ÚNICAMENTE si cumple con los requisitos.

\section{Requerimientos}

- Educación mínima: Universidad/Carrera técnica.

- Años de experiencia: 1.

- Idiomas: Inglés, francés.

- Edad: entre 24 y 54 años.

- Conocimientos: Microsoft Excel, Microsoft Outlook, Microsoft PowerPoint, Microsoft Word.

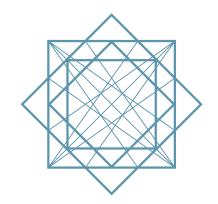

